\title{
Mecanismos da gestão democrática da escola expressos nas normas educacionais brasileiras
}

\author{
Andréia Vicência Vitor Alves ${ }^{1}$ \\ https://orcid.org/0000-0002-5179-4053 \\ Jonata Cristina dos Santos ${ }^{2}$ \\ http://orcid.org/0000-0002-4047-4767
}

\section{Resumo}

O presente artigo analisa como a literatura acadêmica compreende as formas de funcionamento desses mecanismos de gestão. Concluímos que, embora esses mecanismos possibilitem a participação direta e representativa da comunidade escolar, a abertura de espaço para diálogos, debates e discussões no âmbito educacional, eles entram em conflito com o PNE (2014-2024), que apresenta a nomeação de diretores associada à meritocracia e a critérios de desempenho não compatíveis com as características desse tipo de gestão.” por "Assim, o presente estudo tem como intuito apreender como a literatura educacional apresenta essa gestão e seus mecanismos supracitados, a partir de 1988, isso por meio da pesquisa bibliográfica. Concluímos que a gestão democrática tem como mecanismos a participação, a eleição de diretores, os conselhos escolares e a participação na elaboração do PPP, que possibilitam a participação direta e representativa da comunidade escolar; a abertura de espaço para diálogos, debates e discussões no âmbito educacional. Entretanto, o PNE (2014-2024) apresenta a nomeação de diretores associada meritocracia e a critérios de desempenho, que não são considerados características dessa gestão.

Palavras-chave: Gestão Educacional. Gestão Democrática. Participação. Eleição de Diretores. Conselhos de Educação. Projeto Político Pedagógico.

\begin{abstract}
Democratic management is based on Brazilian educational law, since the Federal Constitution of 1988, as a principle to be put into practice in educational institutions. This management model foresees the election of principals, the organization of school councils and the participation in the elaboration of the school pedagogical project as mechanisms of the school management. This article analyzes how the academic literature understands the ways in which these management mechanisms work. We conclude that, although these mechanisms allow the direct and representative participation of the school community, the opening of space for dialogues, debates and discussions in the educational field, they conflict with the PNE (20142024) which presents the appointment of principals associated with the school meritocracy and performance criteria that are not compatible with the characteristics of such management.
\end{abstract}

Keywords: Educational Management. Democratic Management. Participation. Election of Directors. Councils of Education. Pedagogical Political Project.

\footnotetext{
1 Doutora em Educação pela Universidade Federal de Mato Grosso do Sul. É professora adjunta na Universidade Federal da Grande Dourados (UFGD), na graduação em Pedagogia e na Pós-graduação em Educação (mestrado e doutorado). E-mail: andreiaalves2ufgd.edu.br.

2 Mestranda do Programa de Pós-graduação em Educação da Universidade Federal da Grande Dourados (UFGD) e graduada em Pedagogia pela UFGD. E-mail: jonatacristina@gmail.com
} 


\section{Introdução}

Nos anos de 1980 houve movimento pela democratização da sociedade e da educação, tendo como um de seus intuitos a criação de mecanismos de democratização a fim de possibilitar a participação da sociedade no âmbito da educação, na definição de políticas, na administração e no planejamento educacional. O que culminou na aprovação da Constituição Federal de 1988, na qual foi prescrito como um de seus princípios a gestão democrática da educação na forma da Lei (BRASIL, 1988).

Esse princípio foi reafirmado na Lei 9.394, que estabelece a Lei de Diretrizes e Bases da Educação Nacional (LDB), mas que abre mão de uma regulamentação mais precisa dele, deixando a cargo dos sistemas maiores detalhamentos da gestão democrática, ao dar autonomia para os sistemas de ensino definir as normas da gestão democrática do ensino público para a educação básica. A LBD, em seu Art.14, apresenta como princípios dessa gestão a participação dos profissionais da educação na elaboração do Projeto Político Pedagógico (PPP) da escola e a participação da comunidade escolar e local em Conselhos Escolares ou equivalentes (BRASIL, 1996).

Por conseguinte, essa gestão democrática também foi reafirmada na Lei 10.172, que estabelece Plano Nacional de Educação (PNE) com vigência no período de 2001 a 2011 (PNE (2001-2011); e na Lei 13.005, que aprova o PNE que vigorará de 2014 a 2024 (PNE 2014-2024). Ambas normatizações apresentam como características dessa gestão a participação direta e a representativa, os conselhos de educação, a autonomia e o trabalho coletivo, a participação na construção do projeto político-pedagógico e o PNE (2014-2024) traz considerações sobre o processo de escolha de diretores.

Diante disso, esse artigo busca apreender a gestão democrática na literatura educacional, bem como a participação, o Conselho Escolar e o Projeto Político Pedagógico (PPP) que são seus principais mecanismos e estão expressos na normatização educacional que trata do tema a partir de 1988, primeiro momento em que a gestão democrática da educação é apresentada na normatização educacional brasileira. Isso por meio da pesquisa bibliográfica, tendo como fontes livros, capítulo de livros e artigos que tratam dessa temática a partir de então.

Num primeiro momento abarcamos o conceito de gestão democrática da educação e, logo após, a eleição de diretores, a participação, o Conselho Escolar e a elaboração coletiva do Projeto Político Pedagógico como mecanismos dessa gestão.

\section{Gestão democrática da educação}

A gestão democrática como princípio constitucional possibilita aos indivíduos o direito de participação, de intervenção e decisão como meio de buscar seus interesses. Para Alves (2014, p. 22),

[...] a gestão democrática da educação pode ser definida como um processo de caráter político pedagógico e administrativo, no qual se dá participação efetiva, direta e indireta da sociedade em todos os níveis de decisão e execução da educação, com real poder de interferência e manifestação dos anseios comunitários.

Essa gestão possibilita a participação da comunidade em todos os âmbitos da educação, propiciando-a tomar parte das discussões, tomadas de decisões e das ações no âmbito da escola. 
Para Bastos (1999), a gestão democrática se constitui num meio de introduzir a eleição de dirigentes escolares e os conselhos escolares dentro da instituição. É um meio de administrar a escola com as representações de todos os segmentos - professores, pais, alunos e comunidade, de modo que esses possam constituir "núcleos de pressão e exigir do diretor eleito o compromisso com a participação de todos na construção de uma escola democrática" (BASTOS, 1999, p. 29).

Cury (2002, p. 173) considera a gestão democrática como uma gestão de autoridade compartilhada com "transparência e impessoalidade, autonomia e participação, liderança e trabalho coletivo, representatividade e competência". Para ele, essa concepção de gestão é um processo voltado para a "participação e a deliberação pública, além do crescimento dos indivíduos como cidadãos e do crescimento da sociedade enquanto sociedade democrática".

Contribuindo com esse pensamento, Dourado (1988, p. 170) aponta que tal gestão pode ser definida como "processo de aprendizado e de luta política" que possibilita a criação de canais de participação. Spósito (1999) ressalta a gestão democrática como instrumento transformador das práticas pedagógicas, na superação dos desafios para que se formule um novo projeto pedagógico.

Nessa perspectiva, podemos considerar a participação e o diálogo basilares para efetivação da gestão democrática, que tem como finalidade garantir a participação de todos os cidadãos direta ou indiretamente nas tomadas de decisões em todas as esferas da sociedade em assuntos de seus interesses.

Para Cury (2002), essa gestão democrática é considerada um processo dialógico no qual os interlocutores têm condições de expor suas ideias e solucionar conflitos, sendo esse processo "voltado para a participação e a deliberação pública, além do crescimento dos indivíduos como cidadãos e do crescimento da sociedade enquanto sociedade democrática" (CURY, 2002, p. 173).

Essa gestão pode ser definida como processo que possibilita a criação de canais de participação; concretizase na prática social, e dá ao indivíduo autonomia de participação nos espaços onde os conflitos e as estruturas de poder podem ser discutidos (DOURADO, 1988).

Tal gestão tem em vista o ser humano, possibilita um ensino prazeroso que propicie aos alunos o querer aprender, que respeite a sua maneira de pensar e agir, possibilitando, a eles e à comunidade escolar, voz e vez, concorrendo para uma formação crítica dos educandos, voltada à transformação e emancipação humana (ALVES; FREITAS, 2008).

Ela deve ser efetivada por meio de conselhos, colegiados, da participação dos professores, pais, alunos e comunidade na construção de um projeto político-pedagógico e em todos os âmbitos da educação, com autonomia pedagógica, didática e financeira, que vise à melhoria da qualidade da educação.

As eleições de diretores, a participação, os Conselhos Escolares e o PPP são alguns dos mecanismos de gestão democrática significantes no processo de democratização da educação, expressos na normatização educacional. Com isso, a seguir os abordaremos, considerando que são essenciais para a gestão da escola pública. 


\section{Mecanismos de gestão educacional democrática}

No âmbito da gestão escolar os instrumentos democráticos possibilitam a participação da sociedade de modo geral, tornando a escola centro de debates e discussões concernentes a um contexto bem maior que sua própria natureza.

Ao encarregar os sistemas de ensino dos detalhamentos do princípio da gestão democrática, a LDB permitiu que normatizações posteriores definissem tal gestão e a melhor forma de provê-la. Com essa premissa, os PNEs supramencionados sinalizaram ações para a gestão do sistema de educação a serem implantadas em 10 anos. Apresentaram em sua redação que tal gestão deveria ocorrer com a participação da comunidade, a desburocratização, a flexibilidade nas ações dentro da escola, a descentralização de poder, a eleição de diretores, os Conselhos Escolares e a elaboração coletiva do PPP. O que vem sendo reafirmado também nos Planos Estaduais de Educação e nos Planos Municipais que devem estar consoantes ao PNE.

Contudo, tratamos neste artigo apenas da eleição de diretores, da participação, dos conselhos escolares e o PPP como instrumentos fundamentais para uma gestão democrática no contexto escolar, considerando que por si só esses mecanismos não se constituem em tal gestão.

\section{Eleição de diretores}

Desde a década de 1960, com a luta pela democratização dos país e, consequentemente, pela democratização da educação, mecanismos para garantir a gestão democrática no setor educacional foram implantados, a começar pela escolha dos dirigentes escolares.

Segundo Dourado (1998), historicamente, são várias as formas de acesso aos cargos de gestão nas escolas públicas no Brasil, destacando-se, entre elas:

- o diretor livremente indicado pelos poderes públicos - essa modalidade favoreceria o clientelismo, eliminaria qualquer um que se opusesse ao prefeito ou governador. Permite práticas autoritárias nas escolas, evidenciando forte ingerência do Estado na gestão escolar;

- o diretor de carreira - modalidade pouco utilizada, na qual teria acesso ao cargo quem possuísse tempo de serviço, merecimento e/ou distinção, escolarização, entre outros. Representa em tese a meritocracia no setor público, alijando também a participação da comunidade escolar na escolha de seu dirigente;

- o diretor aprovado em concurso público - essa modalidade valoriza as atividades administrativas e burocráticas, secundarizando o processo político-pedagógico. A defesa do concurso público de provas e títulos se constitui em uma bandeira a ser empunhada e efetivada como forma de ingresso na carreira docente. Porém, não é a forma mais apropriada para escolha de dirigentes escolares;

- o diretor indicado por listas tríplices ou sêxtuplas ou processos mistos - consiste na consulta à comunidade escolar, ou a setores dela, para a indicação de nomes dos possíveis dirigentes escolares, a fim de nomeálo e/ou submetê-los a provas ou atividades de avaliação de sua capacidade cognitiva para a gestão da educação; e 
- $\quad$ eleição direta para diretor - as eleições diretas para diretores têm sido a modalidade considerada mais democrática pelos movimentos sociais, inclusive dos trabalhadores da educação em seus sindicatos.

A partir das modalidades supracitadas, a eleição direta para diretor além de ser considerada mais democrática, valoriza a legitimidade do dirigente escolar como coordenador do processo pedagógico no âmbito escolar e pode ser apontada como um canal de democratização das relações escolares (DOURADO, 1988). Constituindo-se em um mecanismo da gestão democrática, ela deve ter a participação dos professores, pais, alunos, demais funcionários e comunidade em geral na escolha do diretor, já que por si só não garante a implementação da gestão democrática na escola, visto que essa implementação deve ser realizada com participação e diálogo, de todos os envolvidos na escola.

O diretor eleito terá o papel de coordenar o trabalho no interior da escola, representar a escola diante do sistema de ensino e da comunidade, assim como descentralizar o poder no interior da escola buscando melhorar a qualidade do processo de ensino-aprendizagem e as condições de vida dos envolvidos na gestão da escola.

Entretanto, o PNE (2014-2024) apresenta critérios de mérito e desempenho para nomeação dos diretores escolares bem como a participação da comunidade, o que não é característica da gestão democrática da educação conforme a literatura educacional, que apresenta como característica dessa gestão a eleição de diretores com a participação direta da comunidade escolar e local na qual a escola está inserida em tal processo eletivo, bem como o trabalho coletivo (ALVES; SANTOS, 2018).

\section{Apontamentos sobre a participação}

A participação, conforme Teixeira (1999, p.187), “significa fazer parte, tomar parte, ser parte de um ato ou processo, de uma atividade pública, de ações coletivas”. Quem participa tem vontade de mudança e se destaca em termos de conhecimentos e valores, faz-se presente no contexto das ações no qual está inserido, dialogando, intervindo e sugerindo ideias, visando o bem coletivo. A participação assegura uma sociedade mais justa, descentralizada de poder e dialógica.

Nas palavras de Lück (2013), a participação requer mobilização dos esforços para superação de comportamentos individualistas e para a construção do espírito de equipe, buscando objetivos assumidos por todos.

Lück (2013) observa a prática diferenciada da participação por sua abrangência e poder de influência. A partir de estudos das formas participativas, a autora identifica o processo de participação como:

- $\quad$ presença - em que o participante é quem pertence a um grupo ou organização, independente da sua atuação nele;

- $\quad$ expressão verbal e discussão de ideias - na qual é dada aos sujeitos a oportunidade de expressarem suas opiniões, de falarem, de debaterem, de discutirem sobre ideias e ponto de vistas;

- representação - de modo que ideias, expectativas, valores, direitos são manifestados e levados em consideração por meio de um representante em um contexto organizado para esse fim; 
- tomada de decisão - que implica em compartilhar responsabilidades de decisões tomadas em conjunto e enfrentar desafios nos avanços para melhoria e transformações necessárias;

- engajamento - que tem em vista envolver-se dinamicamente nos processos sociais assumindo responsabilidades de agir com empenho, competência e dedicação a fim de obter os resultados propostos.

Ainda, segundo a autora, a ação participativa assegura o espírito de equipe mediante certos valores como a ética, a solidariedade, a equidade e o compromisso, dentre outros. Sem eles, a participação no contexto educacional perde sua função social e pedagógica (LUCK, 2013).

A participação é um tema complexo, as distintas formas que apresentam o seu significado e entendimento refletem em seus resultados. Nesse sentido, Motta (2003) propõem cinco formas de participação:

- a participação imposta, que tem como intento a melhoria na organização e nos canais de participação. Ela abre oportunidade, mas não possibilidades a serem exploradas coletivamente;

- a participação conflitual, que é baseada na negociação entre patrões e sindicatos de trabalhadores, excluindo os trabalhadores, uma vez que os sindicatos falam por eles;

- a funcional, caracterizada pela prática recorrente de reuniões de debate, consulta e informação entre patrões e trabalhadores, administradores, funcionários e trabalhadores, unidades organizacionais e níveis hierárquicos em geral;

- a administrativa, organizada por representação semelhante ao plano da administração da educação;

- e a cogestão que é uma forma avançada de participação que implica a codecisão em alguns assuntos e consultas em outros.

Contudo, não é objetivo deste estudo tratar desses formatos participativos de modo aprofundado. As formas de participação mais usuais são a participação direta e a participação indireta ou representativa. A participação direta possibilita aos cidadãos participarem efetivamente das discussões, tomadas de decisões e nas ações, de modo que sua voz seja respeitada e as ações implementadas estejam de acordo com seus anseios. Na participação indireta, os cidadãos elegem um representante para a discussão, tomadas de decisões e realização das ações a seu respeito, participando apenas da eleição de tais representantes.

Tanto a participação direta como a representativa podem ser implementadas na gestão democrática da educação quando essas têm em vista a descentralização do poder, um trabalho coletivo e dialógico e buscam atender aos anseios da comunidade escolar, no entanto a mais utilizada e expressa na normatização educacional é a representativa através dos conselhos de educação.

\section{Os Conselhos Escolares}

No Brasil, os conselhos nas suas diversas modalidades surgiram da conquista de movimentos populares e sindicais por melhores condições de vida e qualidade na/da educação. Os Conselhos Escolares são canais de participação significantes na mobilização da comunidade educativa e implicam tomada de decisão, precedida de 
análise e debate, publicidade na audiência e na visibilidade das mesmas, conforme argumentam Gonh (2011) e Cury (2000).

Cury (2001) aponta que, a rigor, os conselhos concorrem para garantir o acesso e a permanência de todas as crianças, adolescentes, jovens e adultos em escolas de qualidade, que ofertem um ensino com igualdade e oportunidades a todos, sem distinções.

Alves (2014) aponta que os Conselhos Escolares são instrumentos capazes de inserir e envolver a todos no processo de gestão. Teria a tarefa de mediar relações entre a comunidade escolar e a comunidade local, constituindose em um espaço público que concorre para a efetivação da gestão democrática da educação dando lugar à cidadania, autonomia, participação comunitária, ao aprendizado político e social, ao diálogo, à democratização e à reivindicação coletiva, garantindo a participação direta e indireta de todos os segmentos da comunidade, permitindo integração escola-comunidade.

Gonh (2011) pondera que os Conselhos Escolares podem ser tanto instrumentos valiosos para a constituição da gestão democrática e participativa, como também instrumentos de acomodação de conflitos e de integração dos indivíduos em esquemas definidos previamente. Considera, ainda, que eles são espaços com caráter duplo, que tanto podem concorrer para o incentivo do processo de participação sociopolítica como podem também não progredir em termos de participação dos grupos.

Quando se constituem em mecanismo da gestão democrática da educação, buscam ser um elo entre a escola e a comunidade escolar, sendo um espaço de diálogo e trabalho coletivo. A participação representativa tem seu espaço nos Conselhos Escolares quando seus representantes são escolhidos democraticamente através do voto, e eles atuam como um espaço de debates, diálogos, discussões das relações, descentralização de poder, sugestões, troca de ideias.

Tais Conselhos reúnem representantes de diretores, professores, coordenadores pedagógicos, servidores técnico-administrativos, estudantes e pais, que compartilham responsabilidades de ações desenvolvidas na escola. Seu papel é ampliar a participação dos representantes da comunidade local e escolar na gestão administrativa, financeira e pedagógica da escola, monitorando e avaliando a qualidade do ensino e da aprendizagem nela.

Segundo Veiga (2013), os Conselhos como órgão máximo de decisão na escola, defendem uma nova visão de trabalho coletivo, que possibilitam o envolvimento e responsabilidade de seus participantes. Em conjunto com a gestão escolar e a comunidade, podem investigar a realidade escolar e propor soluções, bem como implantar centros de estudos; organizar atividades na área da cultura, lazer e esporte na escola; possibilitar a utilização das dependências dela pela comunidade local; como também concorrer para a elaboração de um PPP que esteja consoante aos anseios dessa comunidade (GONH, 2011).

Desta feita, os Conselhos Escolares como instrumentos da gestão democrática, devem efetivar a participação da sociedade mediante representação, abrir espaço para diálogos, debates e discussões, assim como fortalecer o PPP para a melhoria da qualidade da educação. 


\section{A elaboração coletiva do Projeto Político Pedagógico (PPP)}

O PPP como instrumento da gestão democrática tem a participação da comunidade escolar na sua elaboração. Veiga (2013, p.11) explica o projeto político-pedagógico “[...] como um produto específico que reflete a realidade da escola situada em um contexto mais amplo que a influencia e que pode ser por ela influenciado".

O PPP é o documento que dá vida à escola. Ele tem como intuito apontar o histórico da instituição, a sua missão, o contexto que ela está inserida, as ações que serão desenvolvidas, os problemas a serem resolvidos e os objetivos por ela a serem alcançados. É um dos meios pelo qual a comunidade escolar pode participar democraticamente da educação escolar, sendo “[...] o definidor de critérios para a organização curricular e a seleção de conteúdos" (VEIGA, 2013, p.22).

Ele tem a finalidade de organizar a escola de modo que ela proporcione ao aluno as competências necessárias para interagir em sociedade; concorrer para sua formação no exercício da cidadania; oferecer a ele igualdade de condições; além de propiciar ações que produzam uma aprendizagem significativa.

Esse Projeto é extremamente importante, pois sem ele a escola não teria um caminho certo a seguir e deixaria de exercer sua função social e pedagógica, bem como sua finalidade que se constitui no pleno desenvolvimento do aluno, seu preparo para o exercício da cidadania e sua qualificação para o trabalho, como estabelece o art. 2 da LDB.

Assim, na escola, a elaboração do PPP deve ser realizada coletivamente, de modo que ele seja avaliado, revisado e atualizado sempre que necessário, por todos que atuam diretamente na escola - diretores, coordenadores, professores, pais, alunos e comunidade local.

Para isso, é preciso realizar encontros periódicos para a discussão e avaliação de como as ações estão sendo realizadas pela comunidade escolar e se as ações definidas como prioridade são realmente possíveis de serem alcançadas, além, de acrescentar ou sugerir novas ações para alcançar os objetivos propostos. Quando o PPP é construído pela comunidade escolar possibilita que os anseios desta sejam atendidos.

\section{Considerações finais}

A gestão democrática tem em vista a participação da comunidade escolar, de modo que esta possa intervir e decidir sobre as ações a serem implementadas na escola, de acordo com seus anseios. É firmada na normatização educacional como concepção de gestão que deve ser colocado em prática nas instituições educacionais, mas depende delas a sua materialização e seus mecanismos.

Essa normatização apresenta como mecanismos dessa gestão a participação, a eleição de diretores, os conselhos escolares e a participação na elaboração do PPP, que quando apresentam uma concepção de gestão democrática da educação têm em vista o diálogo, o trabalho coletivo, a transparência, descentralização do poder, autonomia, e assim uma gestão dialógica e aberta à comunidade escolar, que tem em vista seus anseios.

Em suma, os Conselhos Escolares, a eleição de diretores e a construção e implementação do PPP como instrumentos da gestão democrática possibilitam a participação direta e representativa da comunidade escolar, a abertura de espaço para diálogos, debates e discussões no âmbito educacional. Para tanto, é necessário que a 
comunidade escolar participe efetivamente das discussões, tomadas de decisões e execução das ações para que tal gestão seja materializada. Entretanto, o PNE (2014-2024) apresenta a nomeação de diretores associada à meritocracia e a critérios de desempenho, o que possibilita o individualismo e a competição, que não são características da gestão democrática, conforme a literatura educacional, já que essa gestão tem em vista o trabalho coletivo, o diálogo e uma sociedade mais justa e igualitária.

\section{Referências}

ALVES, Andréia Vicência Vitor. Fortalecimento de Conselhos Escolares: propostas e práticas em municípios sul-mato-grossenses. Editora da UFGD, Dourados/MS, 2014.

BASTOS, João Baptista. Gestão democrática da educação: as práticas administrativas e compartilhadas. In: BASTOS, João Baptista. (orgs.). Gestão democrática. Rio de Janeiro: DP\&A: SEPE, 1999. P.7-30.

BRASIL. Constituição (1988). Constituição da República Federativa do Brasil. Brasília: Senado, 1998.

BRASIL. Lei ${ }^{\circ}$ 9.394, de 20 de dezembro de 1996. Estabelece as diretrizes e bases da educação nacional. Brasília: Diário Oficial da República Federativa do Brasil, Poder Executivo, 23 dez. 1996.

BRASIL. Lei n. 10.172, de 9 de janeiro de 2001. Aprova o Plano Nacional de Educação e dá outras providências. Brasília, Senado, 2001.Disponível em: https:/www.planalto.gov.br/ccivil_03/leis/ leis_2001/110172.htm. Acesso em: 02 nov. 2016.

BRASIL. Lei n. 13.005, de 25 de julho de 2014. Aprova o Plano Nacional de Educação - PNE e dá outras providências. Brasília: Senado, 2014. Disponível em: http://www.planalto.gov.br/ccivil_03/ ato2011-2014/2014/1ei/113005.htm>. Acesso em: 02 nov. 2016.

CURY, Carlos Roberto Jamil. Os conselhos de educação e a gestão dos sistemas. In: FERREIRA, Naura Syria Carapeto; AGUIAR, Márcia Ângela da S. (Orgs.). Gestão da educação: impasses, perspectivas e compromissos. São Paulo: Cortez, 2000, p. 43-60.

CURY, Carlos Roberto Jamil. Gestão democrática da educação: experiências e desafios. Revista brasileira de política e gestão da educação, ANPAE, São Bernardo do Campo, v.18, n. 2, p.163-174, jul./dez. 2002.

DOURADO, Luiz Fernando. A escolha de dirigentes escolares: políticas e gestão da educação no Brasil. In: FERREIRA, Naura Syria Carapeto. (Org.). Gestão democrática da educação: atuais tendências, novos desafios. São Paulo: Cortez, 1998, p. 77-95.

GOHN, Maria da Glória. Conselhos gestores e participação sociopolítica. 4 ed. São Paulo: Cortez, 2011, 128 p.

LUCK, Heloisa. A gestão participativa na escola. 11. ed. Petrópolis, RJ: Vozes, 2013, p.29-68. 
MOTTA, Fernando C. Prestes. Administração e participação: reflexões para a educação. Educação e Pesquisa, São Paulo, v. 29, n. 2, p. 369-373, jul./dez. 2003. Disponível em: www.scielo.br/. Acesso em: Agosto. 2017.

SPÓSITO, Marília Pontes. Educação, gestão democrática e participação popular. In: BASTOS, J. B. (org.). Gestão democrática. Rio de Janeiro: DP\&A: SEPE, 1999, p. 45-56.

TEIXEIRA, Elenaldo Celso. As dimensões da participação cidadã. Caderno CRH, Salvador, n. 26/27, p.179-209, jan./dez. 1997.

VEIGA, Ilma Passos Alencastro. Perspectiva para reflexão em torno do Projeto Político Pedagógico. In: VEIGA, Ilma Passos Alencastro.; RESENDE, Lúcia Maria Gonçalves de.(orgs.). Escola: Espaço do Projeto Político Pedagógico. Campinas, SP: Papirus, 2013. p. 9-32.

VEIGA, Zilah de Passos Alencastro. As instâncias colegiadas da escola. In: VEIGA, Ilma Passos Alencastro.; RESENDE, Lúcia Maria Gonçalves de. (Orgs.). Escola: Espaço do Projeto Político Pedagógico. $17^{\circ}$ ed. Campinas, SP: Papirus, 2013, p.113-126.

Recebido em: 31/08/2019

Aprovado em: 04/12/2019 